\title{
Ozonation of Indigo Carmine Enhanced by Fe/Pimenta dioica L. Merrill Particles
}

\author{
Teresa Torres-Blancas, ${ }^{1}$ Gabriela Roa-Morales, ${ }^{1}$ \\ Carlos Barrera-Díaz, ${ }^{1}$ Fernando Ureña-Nuñez, ${ }^{2}$ Julian Cruz-Olivares, ${ }^{1}$ \\ Patricia Balderas-Hernandez, ${ }^{1}$ and Reyna Natividad ${ }^{1}$
}

${ }^{1}$ Universidad Autónoma del Estado de México (UAEMex), Centro Conjunto de Investigación en Química Sustentable (CCIQS),
UAEM-UNAM, Carretera Toluca-Atlacomulco, Km 14.5, 50200 Toluca, MEX, Mexico
${ }^{2}$ Instituto Nacional de Investigaciones Nuclearles (ININ), Carretera México-Toluca s/n, 52750 La Marquesa Ocoyoacac, MEX, Mexico

Correspondence should be addressed to Gabriela Roa-Morales; groam@uaemex.mx and Reyna Natividad; reynanr@gmail.com

Received 2 October 2014; Accepted 17 February 2015

Academic Editor: Meenakshisundaram Swaminathan

Copyright (C) 2015 Teresa Torres-Blancas et al. This is an open access article distributed under the Creative Commons Attribution License, which permits unrestricted use, distribution, and reproduction in any medium, provided the original work is properly cited.

Green synthesis of metallic particles has become an economic way to improve and protect the environment by decreasing the use of toxic chemicals and eliminating dyes. The synthesis of metal particles is gaining more importance due to its simplicity, rapid rate of synthesis of particles, and environmentally friendly. The present work aims to report a novel and environmentally friendly method for the synthesis of iron particles using deoiled Pimenta dioica L. Merrill husk as support. The indigo carmine removal efficiency by ozonation and catalyzed ozonation is also presented. Synthesized materials were characterized by $\mathrm{N}_{2}$ physisorption and scanning electron microscopy (SEM/EDS). By UV-Vis spectrophotometry the removal efficiency of indigo carmine was found to be nearly $100 \%$ after only 20 minutes of treatment under $\mathrm{pH} 3$ and with a catalyst loading of $1000 \mathrm{mgL}^{-1}$. Analytical techniques such as determination of the total organic carbon content (TOC) and chemical oxygen demand (COD) showed that iron particles supported on deoiled Pimenta dioica L. Merrill husk can be efficiently employed to degrade indigo carmine and achieved a partial mineralization (conversion to $\mathrm{CO}_{2}$ and $\mathrm{H}_{2} \mathrm{O}$ ) of the molecule. From the results can be inferred that the prepared biocomposite increases the hydroxyl radicals generation.

\section{Introduction}

Textile industry is the greatest consumer of high quality fresh water per $\mathrm{kg}$ of treated material. Its production processes, due to their nature, significantly contribute to pollution, since the wastewater is a source of persistent organic pollutants. This is reflected on high chemical oxygen demand (COD) values. Textile wastewater also contains chemicals such as formaldehyde, azo dyes, dioxins, and heavy metals [1-3]. These contaminants are mostly toxic, carcinogenic, and persistent. Dyes are mostly complex molecules and are naturally degraded under high temperature, alkaline conditions, ultraviolet (UV) radiation, and other radical initiators generating the formation of by-products many times more toxic to the environment than the original dye [4]. The generated by-products are known to cause perturbations in the aquatic life and food. In addition, textile dyes are designed to be resistant to microbial, chemical, thermal, and photolytic degradation and thus producing recalcitrant compounds [5]. Thus, an effective and economical technique for removing dyes from textile wastewaters is needed. In this sense, several conventional methods for treating textile industry effluents have been studied, such as photodegradation, adsorption, filtration, coagulation, and biological treatments $[6,7]$. However, due to the stability of the molecules of dyes some of these methods are not completely effective and/or viable. In this sense, advanced oxidation processes (AOPs) have been studied in order to destroy the dye molecules, decolorize the wastewater, and reduce organic pollution. Among these advanced oxidation processes (AOPs), ozonation has drawn attention. Ozonation is an effective, versatile, and environmentally sound technique that has been proven as a good 
method for color removal $[8,9]$. It oxidizes organic pollutants via two pathways: direct oxidation with ozone molecules and/or the generation of free-radical intermediates, such as the $\mathrm{HO}^{\circ}$ radical, which is a powerful, effective, and nonselective oxidizing agent $[10,11]$. However, the oxidation rate by ozonation is limited by the chemical and molecular stability of the pollutant $[2,12-14]$. In order to enhance the ozone oxidation capabilities the addition of metallic particles as catalysts has been suggested [12]. In this context, transition metals are preferred since they exhibit properties that promote free radicals production during the ozonation process. Colloidal particles, either alloyed or core-shelled, have attracted significant attention due to new properties that emerge from the combination of different metals (synergistic effect) in the nanoscale and to the consequent enhancement of the physical and chemical properties of the resulting material $[15,16]$. The application of metallic particles supported on solid surfaces has been previously reported $[17,18]$. It was found that the substrates containing immobilized particles have several functions in analytical chemistry. In general terms, the immobilization of particles or nanoparticles on a solid substrate shows several advantages for analytical applications [19]. Regarding advanced oxidation processes, metal-catalyzed ozonations have particularly drawn attention for water decontamination and therefore the use of metallic particles is being extensively investigated [20, 21]. In this context, the main aim of this study is to test a new biocomposite material, which consists of stable iron particles using deoiled Pimenta dioica L. Merrill husk as support. The evaluation of the removal efficiency using ozonation and catalyzed ozonation of indigo carmine is presented. Allspice (Pimenta dioica L. Merrill) belongs to the Myrtaceae family. Mexico exports around 4500 tons per year and half the production is processed in the country. During the oil extraction processes either through steam distillation, hydrodistillation, or supercritical extraction the berry oil yield ranges from 3.0 to $4.5 \%$. The residue of the oil extraction processes is at least 95.5\% in weight, reaching annually 1500 tons in Mexico. Exhausted allspice is a fibrous material that contains $23.1 \%$ cellulose, $8.5 \%$ hemicellulose, and $26.8 \%$ lignin and is the essayed biosupport in this work [22].

\section{Materials and Methods}

2.1. Reagents. The crushed deoiled residue of allspice was obtained as a product of a hydrodistillation process. This waste was first washed with an ethanol-water solution (40$60 \% \mathrm{v} / \mathrm{v}$ ), in order to eliminate colored and remaining substances; later on, it was dried at $70^{\circ} \mathrm{C}$ for $24 \mathrm{~h}$. Once the adsorbent was cooled down, it was sieved through numbers 10,80 , and 170 meshes, obtaining particles sized 2.00, 0.177 , and $0.088 \mathrm{~mm}$, respectively. It was then stored in a desiccator. Sodium hydroxide, sulfuric acid, sodium borohydride, iron sulfate, and indigo carmine (IC) dye analytical grade were purchased from Sigma-Aldrich Chemicals. Ozone was generated in situ from dry air by an ozone generator (Pacific Ozone Technology), with an average ozone production of $0.005 \mathrm{gdm}^{-3}$.

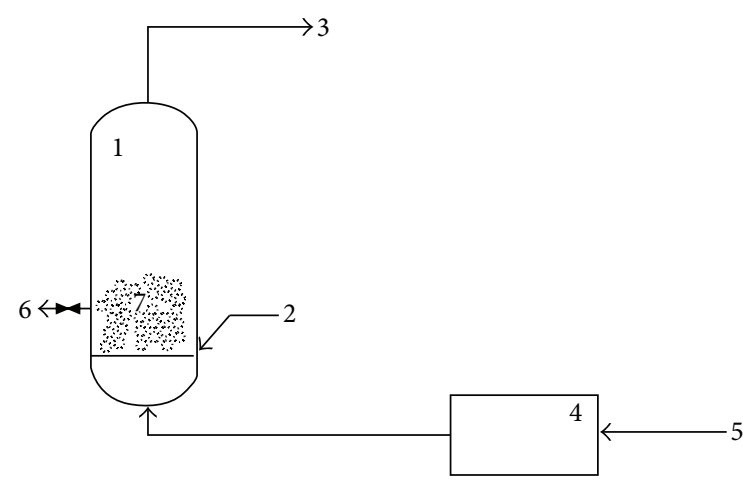

FIGURE 1: Schematic of the apparatus for the ozonation reaction. (1) Upflow glass bubble column reactor. (2) Porous glass (gas diffuser).

(3) Pacific Technology D412 ozone destroyer. (4) Ozone generator.

(5) Dry air inlet. (6) Sample valve. (7) Reaction solution.

2.2. Synthesis of Iron Particles and Iron Supported on Deoiled Allspice Husk. Using porous materials is an interesting alternative to control the stability of zero-valent particles [16]. It has been previously reported that the employment of porous materials improves the stability and catalytic properties of supported metal particles and nanoparticles [6]. In this work deoiled allspice husk was employed as porous material for the synthesis and stabilization of metal particles. The synthesis and support of iron particles on deoiled allspice husk were as follows: approximately $10 \mathrm{~g}$ of deoiled allspice husk (MPS) was placed in a $500 \mathrm{~mL}$ Erlenmeyer flask and mixed with $250 \mathrm{~mL}$ of a $0.01 \mathrm{M} \mathrm{FeSO}_{4}$ solution for $24 \mathrm{~h}$ under continuous stirring at room temperature and $\mathrm{N}_{2}$ atmosphere. Then $10 \mathrm{~mL}$ of $0.1 \mathrm{NaOH}$ solution was added and the resulting slurry was kept under stirring for further half an hour. After this time, $60 \mathrm{~mL}$ of $0.25 \mathrm{M} \mathrm{NaBH}_{4}$ solution was gradually added in order to obtain the metallic particles via reaction (1) [16]. After vacuum filtration, the solid was washed with reagent grade acetone and labelled as MPS/Fe. To synthesize the unsupported iron particles (Fe-NP), $250 \mathrm{~mL}$ of $0.01 \mathrm{M} \mathrm{FeSO}_{4}$ solution was mixed with $15 \mathrm{~mol}$ of $0.1 \mathrm{NaOH}$ solution and $60 \mathrm{~mL}$ of $0.25 \mathrm{M} \mathrm{NaBH}_{4}$. The resulting slurry was also filtered under vacuum and the solid was washed with reagent grade acetone and labelled as Fe-NP:

$$
\begin{aligned}
2 \mathrm{Fe}^{2+} & +2 \mathrm{H}_{2} \mathrm{O}+\mathrm{BH}_{4}^{-}+4 e^{-} \\
\longrightarrow & 2 \mathrm{Fe}_{(\mathrm{s})}+\mathrm{BO}_{2}{ }^{-}+4 \mathrm{H}^{+}+2 \mathrm{H}_{2(\mathrm{~g})} \uparrow
\end{aligned}
$$

2.3. Ozonation. The different ozonation treatments were conducted in a $1 \mathrm{~L}$ upflow bubble column reactor (see Figure 1). Ozone was fed through a gas diffuser with a pore size of $2 \mu \mathrm{m}$. A heated catalytic ozone destructor (Pacific Technology d41202) was employed in order to destroy the excess of ozone in the outlet of the glass bubble column reactor so there was no ozone being discharged to atmosphere. Samples were taken at specific time intervals to be analyzed. All experiments were carried out at room temperature $\left(19^{\circ} \mathrm{C} \pm\right.$ 2), $\mathrm{pH}$ was adjusted at 3.0 with analytical grade sulfuric acid and sodium hydroxide, and the initial IC concentration was $1000 \mathrm{mgL}^{-1}$. The assessed variables were particle size and 
solid concentration. In order to establish the IC adsorption capacity of the synthesized materials, every one of them was placed into an IC solution without feeding ozone. In these experiments the IC concentration at specific time intervals was established by UV-Vis spectrophotometry.

2.4. Chemical Analysis. To determine the concentration of indigo carmine at specific time intervals a spectrophotometric technique was employed. For such a purpose an UVVis Perkin Elmer Lambda 25 model spectrophotometer was used. Samples were analyzed in the range of 200 to $900 \mathrm{~nm}$ with a scan rate of $960 \mathrm{nms}^{-1}$. A maximum absorbance of $610 \mathrm{~nm}$ was found and ascribed to the indigo carmine (IC) dye. The degree of mineralization of indigo carmine was determined by measuring the total organic carbon with a TOC-LCPH/CPN Shimadzu total organic carbon analyzer. The chemical oxygen demand of the samples was determined by using the American Public Health Association (APHA) standard procedures [23].

\subsection{Characterization}

2.5.1. Scanning Electron Microscopy (SEM/EDS). Images were obtained in a JEOL JSM 6510LV instrument at $15 \mathrm{kV}$ with $10 \mathrm{~mm}$ WD using both secondary and backscattered electron signals. Samples were coated with a $20 \mathrm{~nm}$ thin film of gold using Denton Vacuum DESK IV sputtering equipment with a gold target. X-ray energy dispersive spectroscopy analyses were performed in an Oxford PentaFetx5 that was calibrated prior to all analyses with a copper standard.

2.5.2. BET Analysis. Surface area and pore characteristics of deoiled allspice husk original (MPS) and deoiled allspice husk original with iron particles (MPS/Fe) were determined by $\mathrm{N}_{2}$ gas BET analysis (GEMINI 2360 instrument) obtained from nitrogen adsorption at $77 \mathrm{~K}$. The nitrogen adsorption isotherms were recorded up to a relative pressure to assess the total pore volume. Porosity was determined using the pore volume and density.

\section{Results and Discussion}

\subsection{Ozonation}

3.1.1. Effect of Adding Unsupported and Supported Iron Particles on IC Concentration. The ozonation of IC was performed in the bubble column reactor with unsupported iron particles (NP-Fe), original deoiled allspice husk (MPS), and supported iron particles on deoiled allspice husk (MPS/Fe). All experiments were conducted with an initial IC concentration of $1000 \mathrm{mgL}^{-1}$. The initial absorption spectrum shows IC absorption band with a maximum at $610 \mathrm{~nm}$ (see Figure 2). This band was monitored in the ozonation experiments conducted with each material (NP-Fe, MPS, and MPS/Fe). Figure 2 shows that the band at $610 \mathrm{~nm}$ decreases significantly for MPS/Fe at 20 minutes compared to others, suggesting greater effectiveness in the degradation of IC. The absorption band with a maximum at $300 \mathrm{~nm}$ is associated with $\pi$ bonds

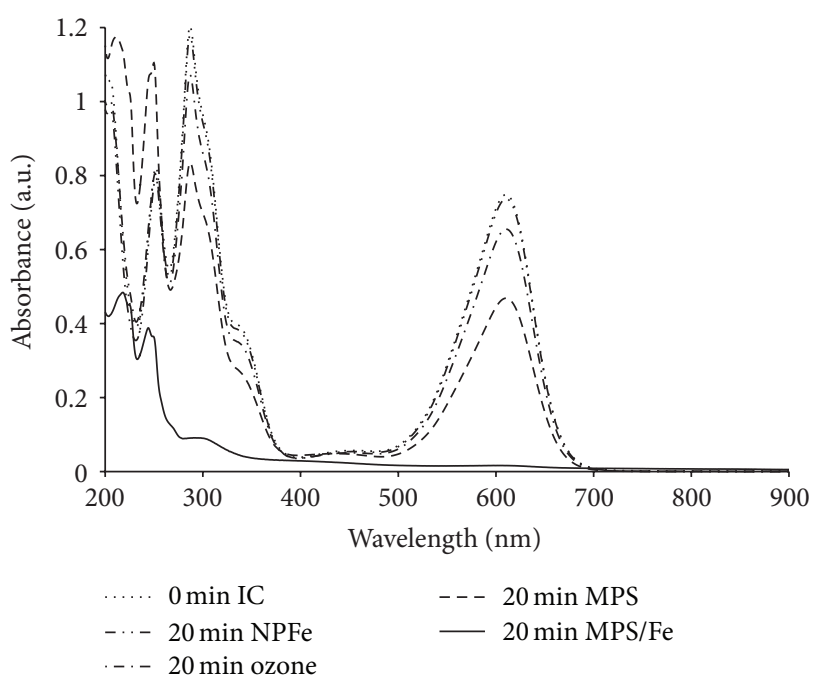

FIGURE 2: Effect of the addition of unsupported and supported iron particles on UV-Vis spectra of indigo carmine solution after 20 minutes of ozonation.

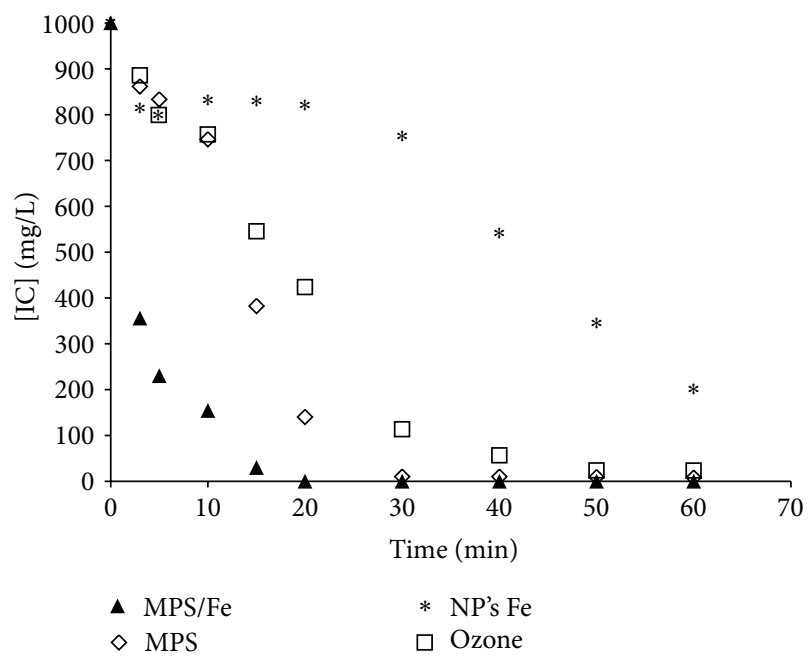

FIGURE 3: Effect of the material and time on IC concentration [^] supported on deoiled allspice husk (MPS/Fe), $[\diamond]$ deoiled allspice husk (MPS), [*] iron metal particles (NP-Fe), and [ם] indigo carmine (IC) only ozone.

and these are decreased by $20 \%$ with the application of ozone $\left(\mathrm{O}_{3}\right)$, ozone/MPS $\left(\mathrm{O}_{3} / \mathrm{MPS}\right)$, ozone/iron $\left(\mathrm{O}_{3}\right.$ /iron particles $\mathrm{NP}-\mathrm{Fe}$ ), indicating that the molecule has not been completely degraded. These $\pi$ bonds are the result of breaking down the IC molecule by the action of free radicals generated during the ozonation process.

Figure 3 shows the IC concentration profile as function of time. It can be observed that the degradation of IC is fastest when the material with the supported iron particles (MPS/Fe) is employed. MPS/Fe leads to nearly complete degradation of the dye after only $20 \mathrm{~min}$ of ozonation. In heterogeneous catalysis the positive effect of the support textural properties on the active sites dispersion and availability is well known. In this context, hydroxo $(\mathrm{OH})$ or oxo $(=\mathrm{O})$ groups in 


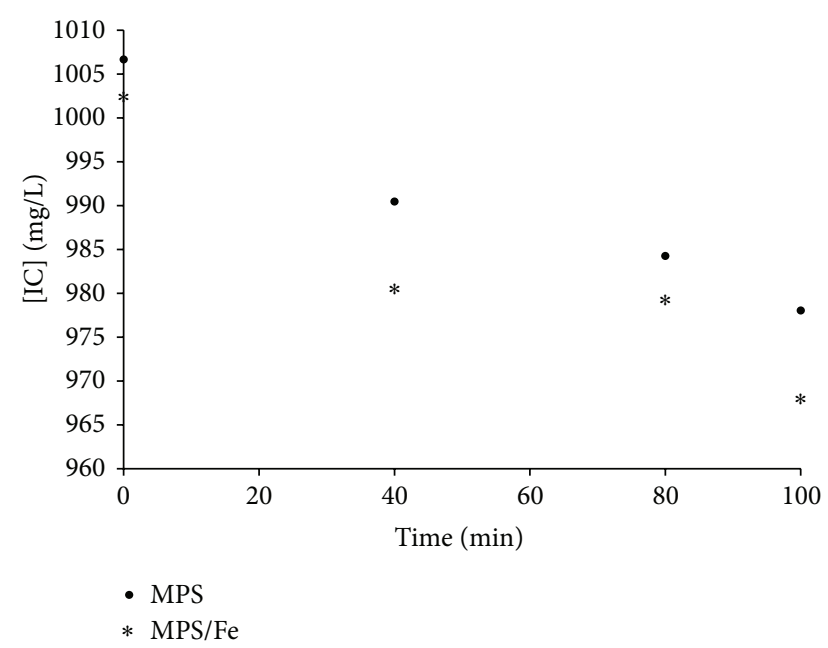

Figure 4: Effect of type of added material and time on IC concentration without ozone.

the synthesis stage provide a greater surface area for the synthesis of metal particles onto the material [22].

The adsorption capacity of the MPS and MPS/Fe materials was tested in the absence of bubbling ozone. Figure 4 shows the results for the two types of materials. None of the two materials (MPS or MPS/Fe) shows an important capacity of adsorption during the contact time.

To elucidate the produced compounds reluctant to further degradation during each treatment, the UV-Vis spectra of the reacting solution as function of time were analyzed (Figure 5). It can be seen from this figure that the spectrum corresponding to the IC has two absorption bands with maxima at 610 and $340 \mathrm{~nm}$. The first band is characteristic of IC and the latter can be ascribed to auxochromes $\left(\mathrm{N}, \mathrm{SO}_{3}\right)$ attached to the benzene ring. One of the main products when the IC is degraded by ozonation is isatin sulfonic acid, which exhibits a maximum of absorption of $304 \mathrm{~nm}$ radiation. The presence of this by-product was detected by analysis of a standard reagent grade in UV-Vis.

When only ozone is applied to the IC solution, it was observed that the maximum absorbance at $610 \mathrm{~nm}$ decreases and this indicates the characteristic blue color is also decreasing. This may be due to the loss of sulphonate group since this works as auxochrome and therefore increases color intensity. From Figure 6, it is evident that the addition of MPS/Fe to the ozonation process decreases the concentration of isatin sulfonic acid generated by the degradation of IC in greater proportion than the other types of solids. It is worth observing that the support does also have a positive effect on isatin degradation. This, however, is considerably slower than when MPS/Fe is employed. Thus, the use of MPS/Fe not only enhances the IC degradation but also markedly reduces the concentration of the main subproduct (isatin sulfonic acid) generated during the ozonation process.

3.1.2. Effect of Adding Unsupported and Supported Iron Particles on Total Organic Carbon and Chemical Oxygen Demand. Table 1 shows that the use of MPS increases the total carbon

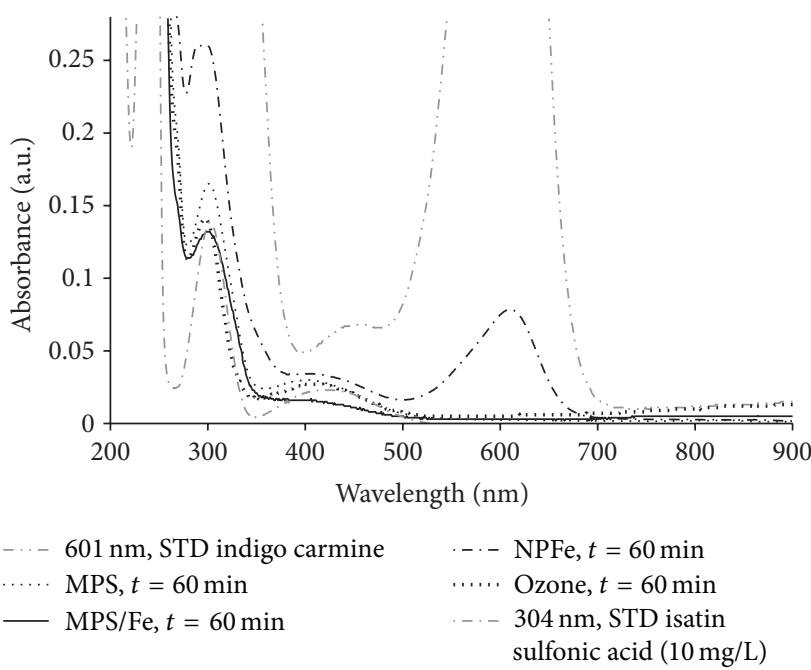

FIgURE 5: Effect of added material type on the ozonation process on UV-Vis spectra. Reaction time: 60 minutes.

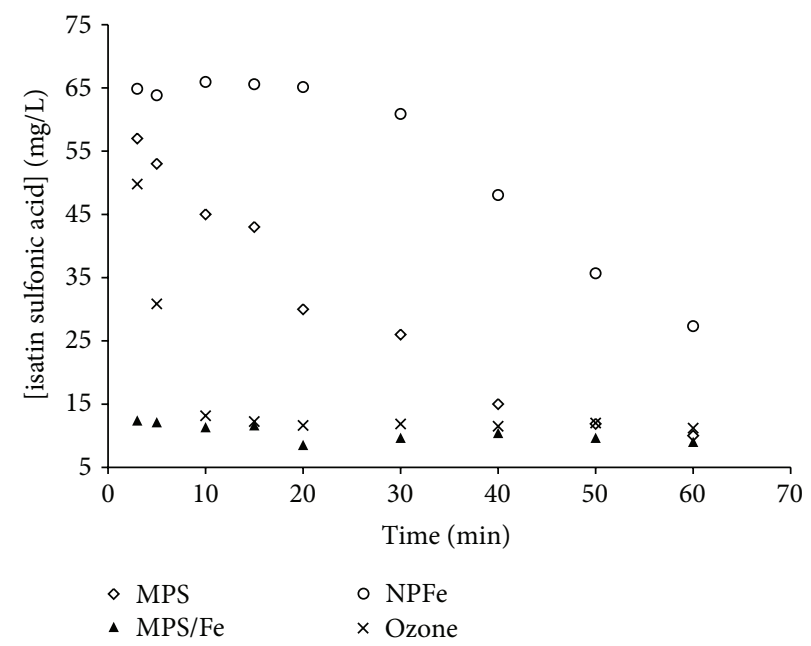

FIGURE 6: Effect of the tested materials on Isatin sulfonic acid concentration.

TABLE 1: Effect of solid material on the final total organic carbon content.

\begin{tabular}{lcccc}
\hline & $\mathrm{MPS}_{3} \mathrm{O}_{3}$ & $\mathrm{MPS} / \mathrm{Fe}-\mathrm{O}_{3}$ & $\mathrm{NP}-\mathrm{Fe}$ & $\mathrm{O}_{3}$ \\
\hline $\begin{array}{l}\text { Total organic carbon } \\
\left(\mathrm{mgL}^{-1}\right) 20 \text { min }\end{array}$ & $272 \pm 5$ & $48 \pm 5$ & $80 \pm 5$ & $202 \pm 5$ \\
$\begin{array}{l}\text { Total carbon } \\
\left(\mathrm{mgL}^{-1}\right) 20 \text { min }\end{array}$ & $274 \pm 5$ & $50 \pm 5$ & $82 \pm 5$ & $205 \pm 5$ \\
$\begin{array}{l}\text { Inorganic carbon } \\
\left(\mathrm{mgL}^{-1}\right) 20 \text { min }\end{array}$ & $3 \pm 5$ & $1 \pm 5$ & $3 \pm 5$ & $3 \pm 5$ \\
\hline
\end{tabular}

Initial total organic carbon $=202 \pm 5 \mathrm{mgL}^{-1}$.

(TOC) during the degradation of IC. This can be ascribed to the degradation of the deoiled crushed material during the ozonation process. Nonetheless, the addition of supported iron particles to the ozonation process substantially enhances total organic carbon removal. Table 1 shows that the use 


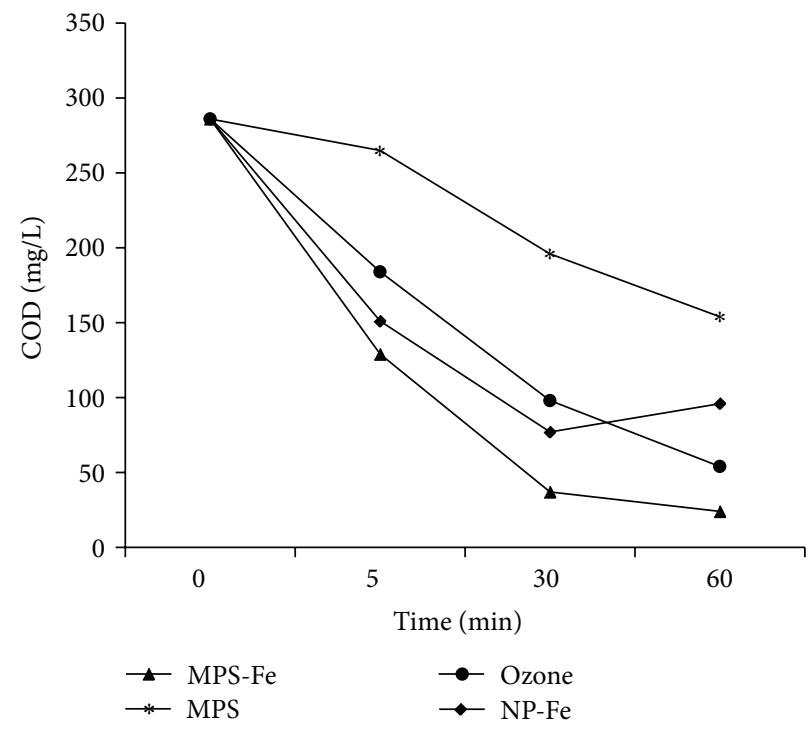

(a)

Indigo carmine

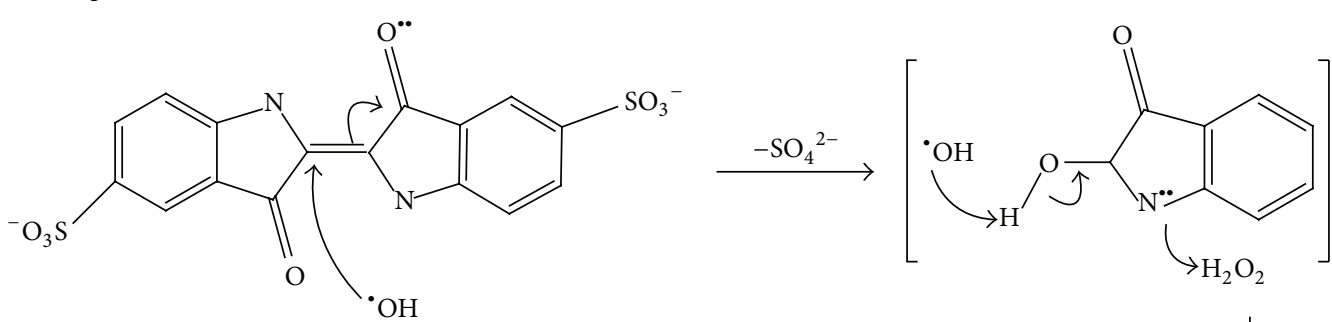

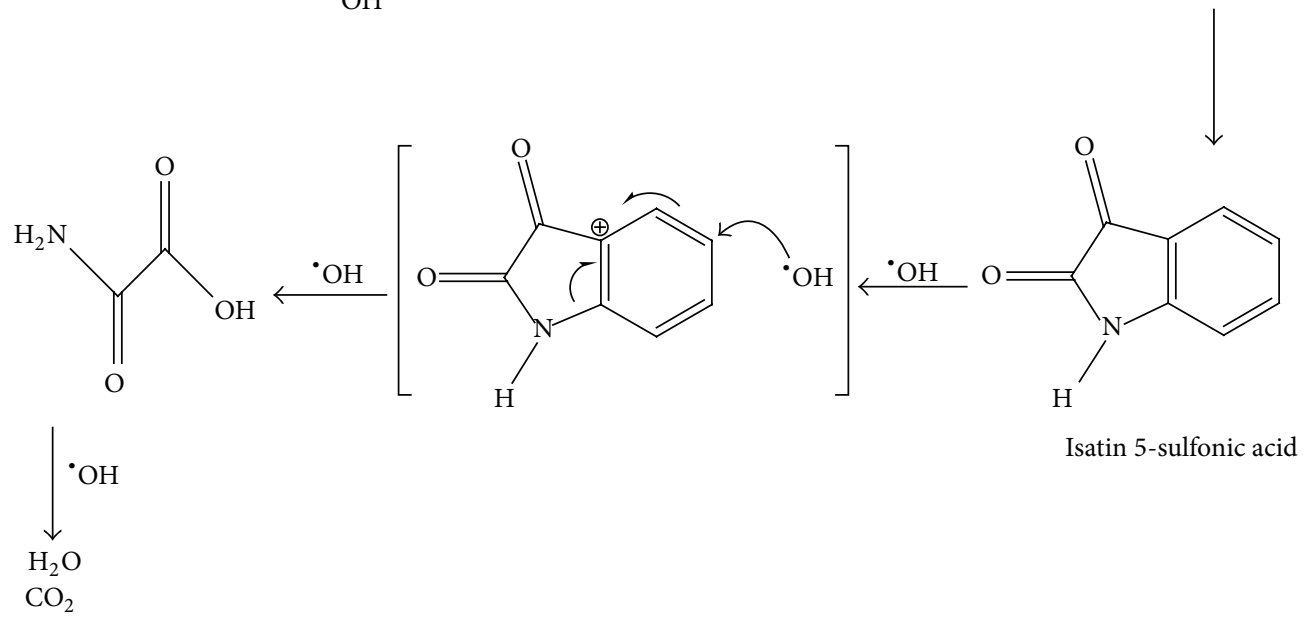

(b)

FIGURE 7: (a) Effect of catalyst type on chemical oxygen demand (COD); (b) proposed indigo carmine degradation mechanism.

of MPS/Fe not only makes IC degradation faster but also inhibits degradation of the support. According to the analysis of total organic carbon the addition of MPS/Fe leads to a $76 \%$ removal of TOC after only 20 minutes of treatment. At the same reaction time, ozone alone does not reduce TOC at all. This can be ascribed to the ozone incapacity to further degrade the isatin molecule.

Figure 7 confirms that the IC oxidation degree strongly depends on the type of added material during the ozonation process and this is given in terms of chemical oxygen demand (COD). These results are in concordance with TOC measurements. The effect of the addition of MPS/Fe on the removal of indigo carmine by ozonation offers a synergistic action that increases the rate of degradation of indigo carmine (Figure 7). The formation of reactive oxidizing species, that is, free radicals $\left(\mathrm{HO}^{*}\right)$ during the ozonation process, concomitantly generates other radicals and hydrogen peroxide. Hence, the use of MPS/Fe introduces new reactions, mainly fenton 
type, that positively impact the mineralization and oxidation degree of the IC solution.

The effect of the addition of MPS/Fe to the ozonation process generates a production of free radicals not governed by the reaction $(2)-(4)$. The ozone reacts in solution to generate the hydroxyl radical $\left(\mathrm{HO}^{\circ}\right)$ and radicals superoxide (2), which are consumed in the production of hydrogen peroxide (2)-(3):

$$
\begin{aligned}
& \mathrm{O}_{3}+\mathrm{H}_{2} \mathrm{O} \longrightarrow 2 \mathrm{HO}^{\bullet}+\mathrm{O}_{2} \\
& \mathrm{O}_{3}+\mathrm{HO}^{\bullet} \longrightarrow \mathrm{HO}_{2}^{\bullet}+\mathrm{O}_{2} \longleftrightarrow \mathrm{O}_{2}^{\bullet}+\mathrm{H}^{+} \\
& 2 \mathrm{HO}_{2}^{\bullet} \longrightarrow \mathrm{O}_{2}+\mathrm{H}_{2} \mathrm{O}_{2}
\end{aligned}
$$

The synthesized zero-valent particles $\left(\mathrm{Fe}^{0}\right)$ are expected to be readily oxidized. However, the IC degradation results suggest that the support allows the iron particles to exhibit a catalytic effect on the generation of free radicals $\left(\mathrm{HO}^{\circ}\right)$. This effect may be related to the interaction of the iron particles with the support surface $[24,25]$. As consequence, this catalytic capability is rather diminished when the iron particles are not supported. Actually, because of previous reports [24, 26, 27], when the ozone is combined with MPS/Fe, the intensification of $\mathrm{HO}^{\circ}$ production was expected. The ferrous specie in the composite MPS/Fe by means of the following reactions may produce the ferrous specie involved in reaction

$$
6 \mathrm{H}^{+}+\mathrm{O}_{3}+\mathrm{FeO} \longrightarrow \mathrm{FeO}^{2+}+3 \mathrm{H}_{2} \mathrm{O}
$$

So that $\mathrm{FeO}^{2+}$ reacts with hydrogen peroxide (traces of oxygen peroxide generated from ozone reactions (2)-(4)) to generate free radicals. Then the degradation of organic matter via free radicals as shown in the following reaction becomes plausible $[12,28,29]$ :

$$
\mathrm{FeO}^{2+}+\mathrm{H}_{2} \mathrm{O}_{2} \longrightarrow \mathrm{FeO}^{3+}+\mathrm{HO}^{\bullet}+\mathrm{OH}^{-}
$$

$\mathrm{Fe}^{3+}$ species may be going back to $\mathrm{Fe}^{2+}$ by means of the following reaction [27]:

$$
\begin{gathered}
\mathrm{Fe}^{3+}+\mathrm{H}_{2} \mathrm{O}_{2} \longrightarrow \mathrm{Fe}^{2+}+\mathrm{HO}_{2}{ }^{\bullet}+\mathrm{H}^{+} \\
\mathrm{RH}+\mathrm{HO}^{\bullet} \longrightarrow \mathrm{R}^{\bullet}+\mathrm{H}_{2} \mathrm{O}
\end{gathered}
$$

Therefore, when adding the MPS/Fe to the ozonation process this is catalyzed. This catalytic effect of $\mathrm{Fe}^{2+}$ on ozonation has been previously recognized $[9,12]$. Therefore, the synergistic effect for the generation of free radicals $\left(\mathrm{HO}^{\circ}, \mathrm{HO}_{2}{ }^{\circ}\right)$ via ozonation reactions (2)-(4) and catalyzed ozonation reactions with supported iron (5)-(7) cannot be neglected.

Under this scheme the degradation of IC towards isatin and its products has been suggested [18] to occur according to the mechanism depicted in Figure 7.

3.1.3. Effect of Particle Size. Also the effect of particle size of the MPS/Fe material was evaluated. Three different particle sizes were tested $2.00,0.177$, and $0.088 \mathrm{~mm}$. The initial concentration of IC was $1000 \mathrm{mgL}^{-1}$ and the reaction time was $60 \mathrm{~min}$. The results are shown in Figure 8 and suggest

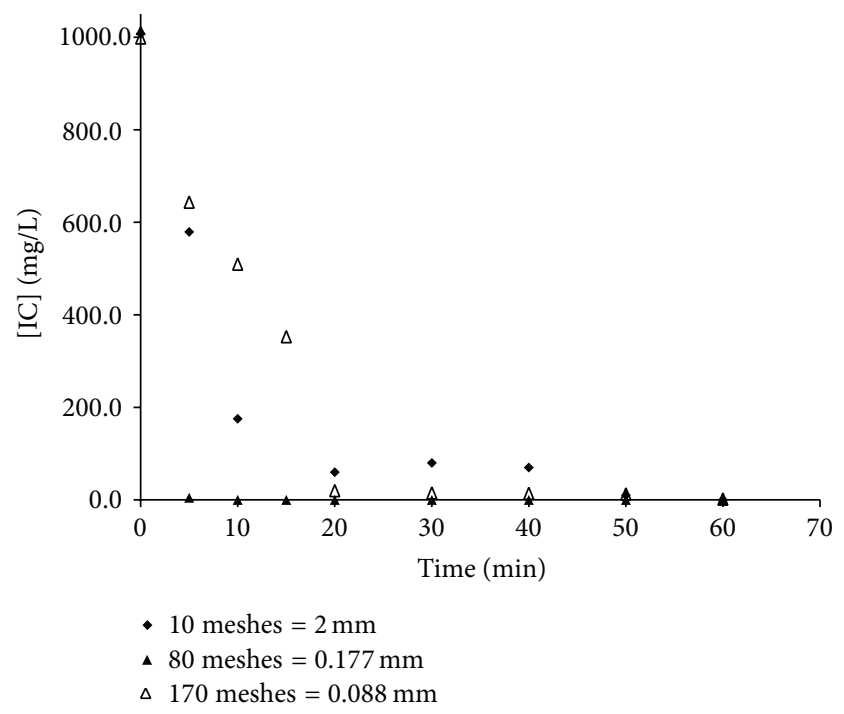

FIGURE 8: Effect of particle size of supported iron particles on indigo carmine concentration profile.

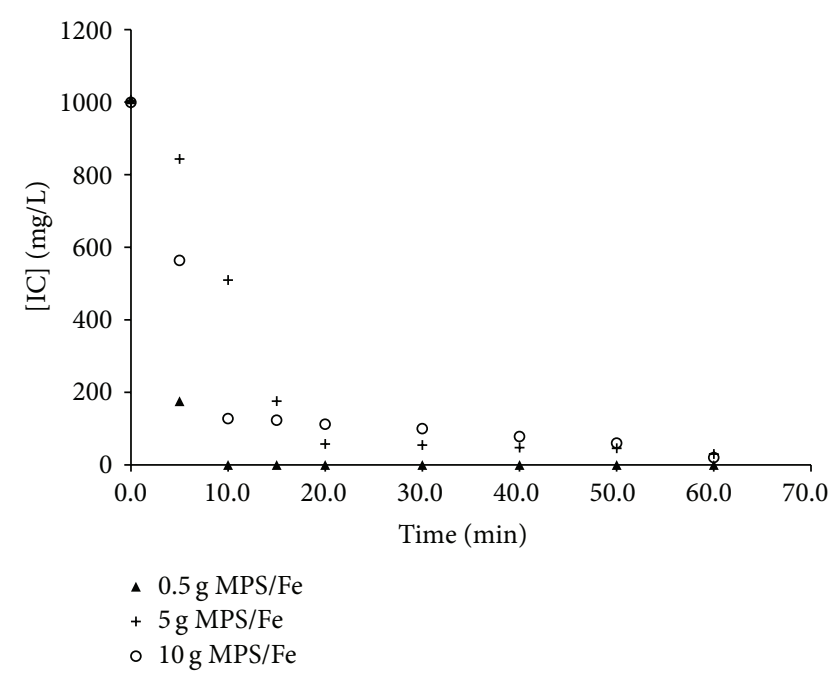

FIGURE 9: Effect catalyst loading on indigo carmine concentration profile.

the presence of liquid-solid and intraparticle mass transport resistances that are presumably minimized when the particle size is $0.177 \mathrm{~mm}$ ( $80 \mathrm{mesh}$ ) as a result of the best and faster degradation of the dye used over the others conditions tested. It is worth noticing that the effect of adsorption was evaluated for all tested materials without the presence of ozone. The results indicated that this phenomenon is negligible for all materials. The unsupported iron particles (NP-Fe) did not exhibit good efficiency in contrast to the supported MPS/Fe.

3.1.4. Effect of Catalyst Concentration. In order to study the effect of this variable three experiments with their corresponding repetitions were conducted. At all experiments the initial concentration of IC were $1000 \mathrm{mgL}^{-1}$ and the reaction time was $60 \mathrm{~min}$. Figure 9 shows the positive effect 


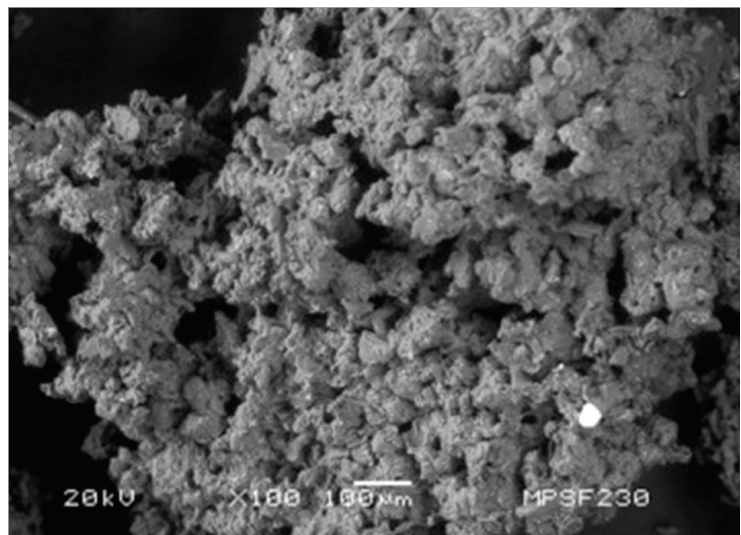

(a)

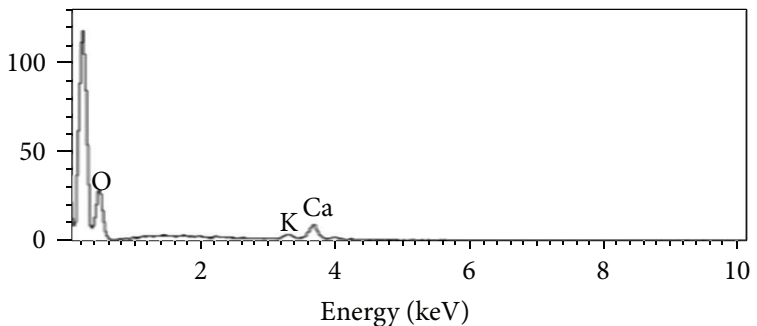

(b)

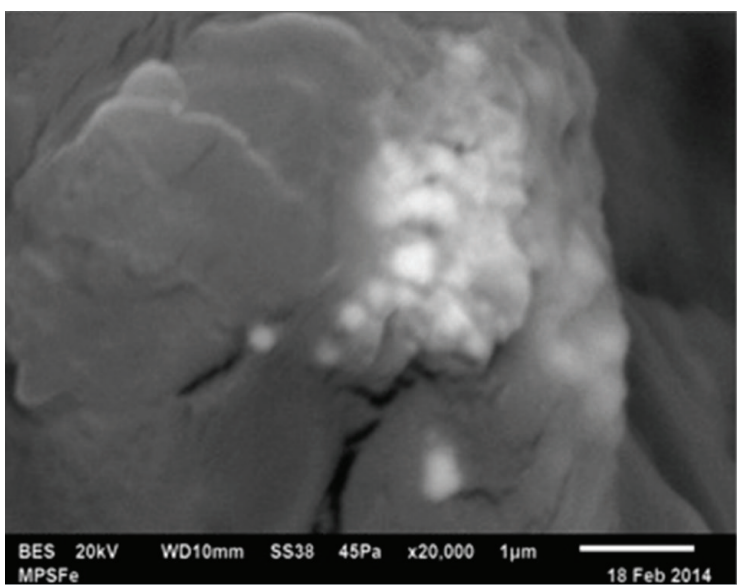

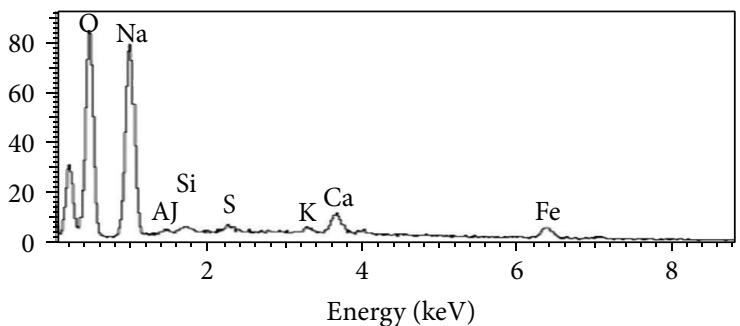

(c)

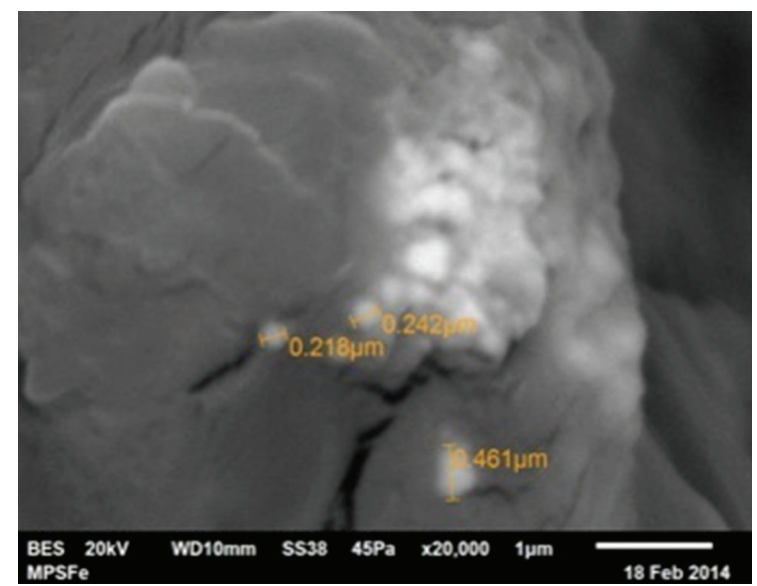

(d)

FIGURE 10: SEM/EDS images for the synthesized materials.

on IC removal when using a $[\mathrm{MPS} / \mathrm{Fe}]=1000 \mathrm{mgL}^{-1}$. The presence of the MPS/Fe enhances the ozonation process, and its concentration has a strong influence over the dye degradation. The IC degradation rate increases when mass of MPS/Fe increases and this is also an indicative of the liquidsolid mass transfer resistance being negligible. It is worth pointing out that the removal of IC by adsorption onto the MPS/Fe particles was found to be negligible. Only $1.8 \%$ of IC was removed by this phenomenon.

\subsection{Materials Characterization}

3.2.1. SEM/EDS and Elemental Analysis. SEM micrographs of MPS and MPS/Fe materials in Figure 10(a) show the parent supports as amorphous. These remained unchanged after the deposition of iron. In the elemental analysis it was found that the material elements of the MPS might be acting as natural material (peaks of $\mathrm{C}, \mathrm{O}, \mathrm{K}$, and $\mathrm{Ca}$, which are typical elements of the natural materials) as shown in Figure 10(b). As expected, iron was detected on the MPS/Fe sample (see Figure 10(c)). The SEM/EDS analysis allows identifying iron particles of approximately $250 \mathrm{~nm}$ in size (Figure 10(d)). It is important to note that the increase in oxygen observed in the MPS/Fe sample suggests the presence of $\mathrm{FeO}^{2+}$ species in contrast with the support alone (MPS). The decrease in weight percent of carbon observed in the MPS/Fe sample (see Table 2) may be due to the coating of the surface by iron particles. 
TABLE 2: Characteristics of catalytic materials.

\begin{tabular}{lcc}
\hline & MPS & MPS/Fe \\
\hline Specific surface area $\left(\mathrm{m}^{2} \mathrm{~g}^{-1}\right)$ & 2.40 & 4.58 \\
$\begin{array}{l}\text { Cumulative pore volume }\left(\mathrm{cm}^{3}\right. \\
\left.(\mathrm{STP}) \mathrm{g}^{-1}\right)\end{array}$ & 0.55 & 1.05 \\
Mean pore diameter $(\mathrm{nm})$ & 4.45 & 6.61 \\
Total pore volume $\left(p / p_{o}\right)=0.990$ & $2.67 E-03$ & $7.58 E-3$ \\
$\left(\mathrm{~cm}^{3} \mathrm{~g}^{-1}\right)$ & $54.61 \%$ & $17.29 \%$ \\
Carbon & $42.84 \%$ & $59.65 \%$ \\
Oxygen & $0.57 \%$ & $20.76 \%$ \\
Sodium & $1.99 \%$ & $0.58 \%$ \\
Calcium & $0 \%$ & $1.72 \%$ \\
Iron & &
\end{tabular}

3.2.2. $N_{2}$ Physisorption. The results in Table 2 show that $\mathrm{MPS} / \mathrm{Fe}$ has a greater specific surface area. This increase may be the consequence of the chemical treatment conducted on the husk during the catalytic system preparation.

\section{Conclusions}

Unsupported and supported iron particles were synthesized via a relatively low cost method. Indigo carmine removal by ozonation and ozonation with unsupported and supported Fe on a biomaterial was studied. MPS/Fe substantially improves the degradation of indigo carmine and of the generated subproducts during the ozonation process. Catalyzed ozonation leads to attain a reaction rate twice faster than ozonation alone. The use of the MPS/Fe allows the removal of $76 \%$ of TOC after only $20 \mathrm{~min}$ of ozonation. It was found that the synthesized materials did not exhibit significant adsorption properties.

\section{Conflict of Interests}

The authors declare that there is no conflict of interests regarding the publication of this paper.

\section{Acknowledgments}

The first author acknowledges the scholarship 248402 from CONACyT to pursue her postgraduate studies. PRODEP is also acknowledged for financial support through project 103.5/13/5257.

\section{References}

[1] C. Tang and V. Chen, "Nanofiltration of textile wastewater for water reuse," Desalination, vol. 143, no. 1, pp. 11-20, 2002.

[2] A. Bes-Piá, J. A. Mendoza-Roca, M. I. Alcaina-Miranda, A. Iborra-Clar, and M. I. Iborra-Clar, "Reuse of wastewater of the textile industry after its treatment with a combination of physico-chemical treatment and membrane technologies," Desalination, vol. 149, no. 1-3, pp. 169-174, 2002.

[3] P. C. Vandevivere, R. Bianchi, and W. Verstraete, "Review: treatment and reuse of wastewater from the textile wet-processing industry: review of emerging technologies," Journal of Chemical Technology \& Biotechnology, vol. 72, no. 4, pp. 289-302, 1998.

[4] K. Santhy and P. Selvapathy, "Removal of reactive dyes from wastewater by adsorption on coir pith activated carbon," Bioresource Technology, vol. 97, no. 11, pp. 1329-1336, 2006.

[5] A. D. Bokare, R. C. Chikate, C. V. Rode, and K. M. Paknikar, "Iron-nickel bimetallic nanoparticles for reductive degradation of azo dye Orange $\mathrm{G}$ in aqueous solution," Applied Catalysis B: Environmental, vol. 79, no. 3, pp. 270-278, 2008.

[6] F. Pena-Pereira, R. M. B. O. Duarte, and A. C. Duarte, "Immobilization strategies and analytical applications for metallic and metal-oxide nanomaterials on surfaces," TrAC-Trends in Analytical Chemistry, vol. 40, pp. 90-105, 2012.

[7] A. Majcen, L. Marechal, and B. Križanec, "Textile finishing industry as an important source of organic pollutants," in Organic Pollutants Ten Years after the Stockholm ConventionEnvironmental and Analytical Update, InTech, 2012.

[8] P. Cañizares, R. Paz, C. Sáez, and M. A. Rodrigo, "Costs of the electrochemical oxidation of wastewaters: a comparison with ozonation and Fenton oxidation processes," Journal of Environmental Management, vol. 90, no. 1, pp. 410-420, 2009.

[9] A. C. Quiroz, C. Barrera-Díaz, G. Roa-Morales, P. B. Hernández, R. Romero, and R. Natividad, "Wastewater ozonation catalyzed by iron," Industrial and Engineering Chemistry Research, vol. 50, no. 5, pp. 2488-2494, 2011.

[10] W. P. Kwan and B. M. Voelker, "Rates of hydroxyl radical generation and organic compound oxidation in mineral-catalyzed fenton-like systems," Environmental Science and Technology, vol. 37, no. 6, pp. 1150-1158, 2003.

[11] A. H. Gemeay, I. A. Mansour, R. G. El-Sharkawy, and A. B. Zaki, "Kinetics and mechanism of the heterogeneous catalyzed oxidative degradation of indigo carmine," Journal of Molecular Catalysis A: Chemical, vol. 193, no. 1-2, pp. 109-120, 2003.

[12] M. Bernal, R. Romero, G. Roa, C. Barrera-Díaz, T. TorresBlancas, and R. Natividad, "Ozonation of indigo carmine catalyzed with Fe-pillared clay," International Journal of Photoenergy, vol. 2013, Article ID 918025, 7 pages, 2013.

[13] M. Faouzi, P. Cañizares, A. Gadri et al., "Advanced oxidation processes for the treatment of wastes polluted with azoic dyes," Electrochimica Acta, vol. 52, no. 1, pp. 325-331, 2006.

[14] N. Gandra, A. T. Frank, O. Le Gendre et al., "Possible singlet oxygen generation from the photolysis of indigo dyes in methanol, DMSO, water, and ionic liquid, 1-butyl-3methylimidazolium tetrafluoroborate," Tetrahedron, vol. 62, no. 46, pp. 10771-10776, 2006.

[15] R. Sankar, P. Manikandan, V. Malarvizhi, T. Fathima, K. S. Shivashangari, and V. Ravikumar, "Green synthesis of colloidal copper oxide nanoparticles using Carica papaya and its application in photocatalytic dye degradation," Spectrochimica ActaPart A: Molecular and Biomolecular Spectroscopy, vol. 121, pp. 746-750, 2014.

[16] V. K. Vidhu and D. Philip, "Catalytic degradation of organic dyes using biosynthesized silver nanoparticles," Micron, vol. 56, pp. 54-62, 2014.

[17] G. Carja, E. Husanu, C. Gherasim, and H. Iovu, "Layered double hydroxides reconstructed in $\mathrm{NiSO} 4$ aqueous solution as highly efficient photocatalysts for degrading two industrial dyes," Applied Catalysis B: Environmental, vol. 107, no. 3-4, pp. 253-259, 2011.

[18] C. Flox, S. Ammar, C. Arias, E. Brillas, A. V. Vargas-Zavala, and R. Abdelhedi, "Electro-Fenton and photoelectro-Fenton 
degradation of indigo carmine in acidic aqueous medium," Applied Catalysis B: Environmental, vol. 67, no. 1-2, pp. 93-104, 2006.

[19] X. Weng, Z. Chen, M. Megharaj, and R. Naidu, "Clay supported bimetallic Fe/Ni nanoparticles used for reductive degradation of amoxicillin in aqueous solution: characterization and kinetics," Colloids and Surfaces A: Physicochemical and Engineering Aspects, vol. 443, pp. 404-409, 2014.

[20] P. Vasileva, B. Donkova, I. Karadjova, and C. Dushkin, "Synthesis of starch-stabilized silver nanoparticles and their application as a surface plasmon resonance-based sensor of hydrogen peroxide," Colloids and Surfaces A: Physicochemical and Engineering Aspects, vol. 382, no. 1-3, pp. 203-210, 2011.

[21] A. R. Khataee, V. Vatanpour, and A. R. A. Ghadim, "Decolorization of C.I. Acid Blue 9 solution by UV/Nano-TiO 2 , Fenton, Fenton-like, electro-Fenton and electrocoagulation processes: a comparative study," Journal of Hazardous Materials, vol. 161, no. 2-3, pp. 1225-1233, 2009.

[22] T. Torres-Blancas, G. Roa-Morales, C. Fall, C. Barrera-Díaz, F. Ureña-Nuñez, and T. B. Pavón Silva, "Improving lead sorption through chemical modification of de-oiled allspice husk by xanthate," Fuel, vol. 110, pp. 4-11, 2013.

[23] American Public Health Association American Water Works Association/Water Environment Federation, Standard Methods for the Examination of Water and Wastewater, American Public Health Association American Water Works Association/Water Environment Federation, 20th edition, 1998.

[24] W. P. Kwan and B. M. Voelker, "Influence of electrostatics on the oxidation rates of organic compounds in heterogeneous fenton systems," Environmental Science and Technology, vol. 38, no. 12, pp. 3425-3431, 2004.

[25] P. Cañizares, M. Hernández-Ortega, M. A. Rodrigo, C. E. Barrera-Díaz, G. Roa-Morales, and C. Sáez, "A comparison between conductive-diamond electrochemical oxidation and other advanced oxidation processes for the treatment of synthetic melanoidins," Journal of Hazardous Materials, vol. 164, no. 1, pp. 120-125, 2009.

[26] M. A. Al-Shamsi, N. R. Thomson, and S. P. Forsey, "Iron based bimetallic nanoparticles to activate peroxygens," Chemical Engineering Journal, vol. 232, pp. 555-563, 2013.

[27] J. De Laat, H. Gallard, S. Ancelin, and B. Legube, "Comparative study of the oxidation of atrazine and acetone by $\mathrm{H}_{2} \mathrm{O}_{2} / \mathrm{UV}$, $\mathrm{Fe}(\mathrm{III}) / \mathrm{UV}, \mathrm{Fe}(\mathrm{III}) / \mathrm{H}_{2} \mathrm{O}_{2} / \mathrm{UV}$ and $\mathrm{Fe}(\mathrm{II})$ or $\mathrm{Fe}(\mathrm{III}) / \mathrm{H}_{2} \mathrm{O}_{2}$," Chemosphere, vol. 39, no. 15, pp. 2693-2706, 1999.

[28] M. A. García-Morales, G. Roa-Morales, C. Barrera-Díaz, B. Bilyeu, and M. A. Rodrigo, "Synergy of electrochemical oxidation using boron-doped diamond (BDD) electrodes and ozone $\left(\mathrm{O}_{3}\right)$ in industrial wastewater treatment," Electrochemistry Communications, vol. 27, pp. 34-37, 2013.

[29] K. C. Pillai, T. O. K. Kwon, and I. S. Moon, "Degradation of wastewater from terephthalic acid manufacturing process by ozonation catalyzed with $\mathrm{Fe}^{2+}, \mathrm{H}_{2} \mathrm{O}_{2}$ and UV light: direct versus indirect ozonation reactions," Applied Catalysis B: Environmental, vol. 91, no. 1-2, pp. 319-328, 2009. 

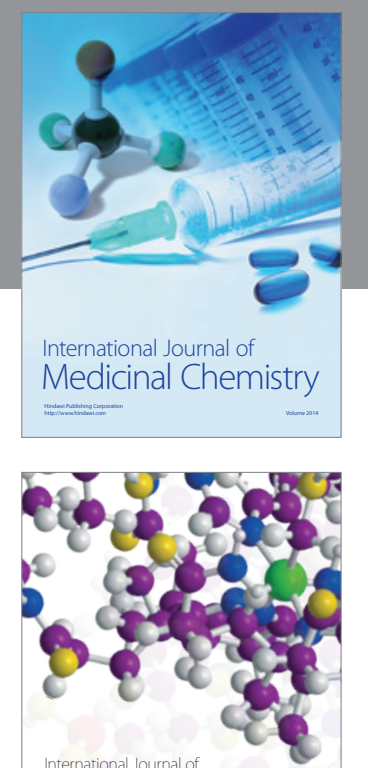

\section{Carbohydrate} Chemistry

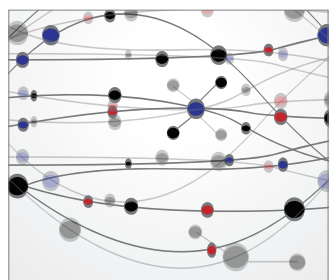

The Scientific World Journal
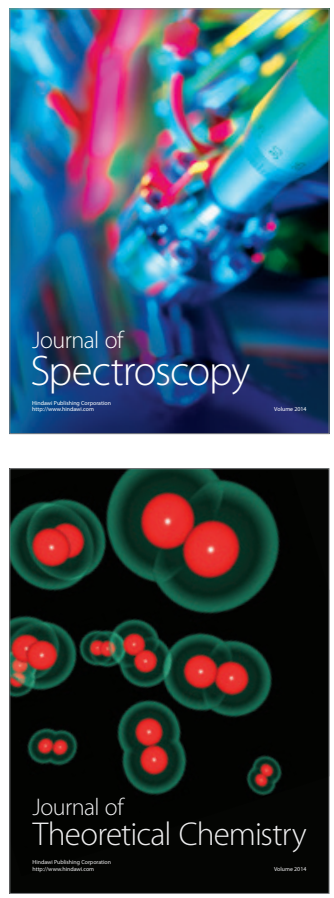
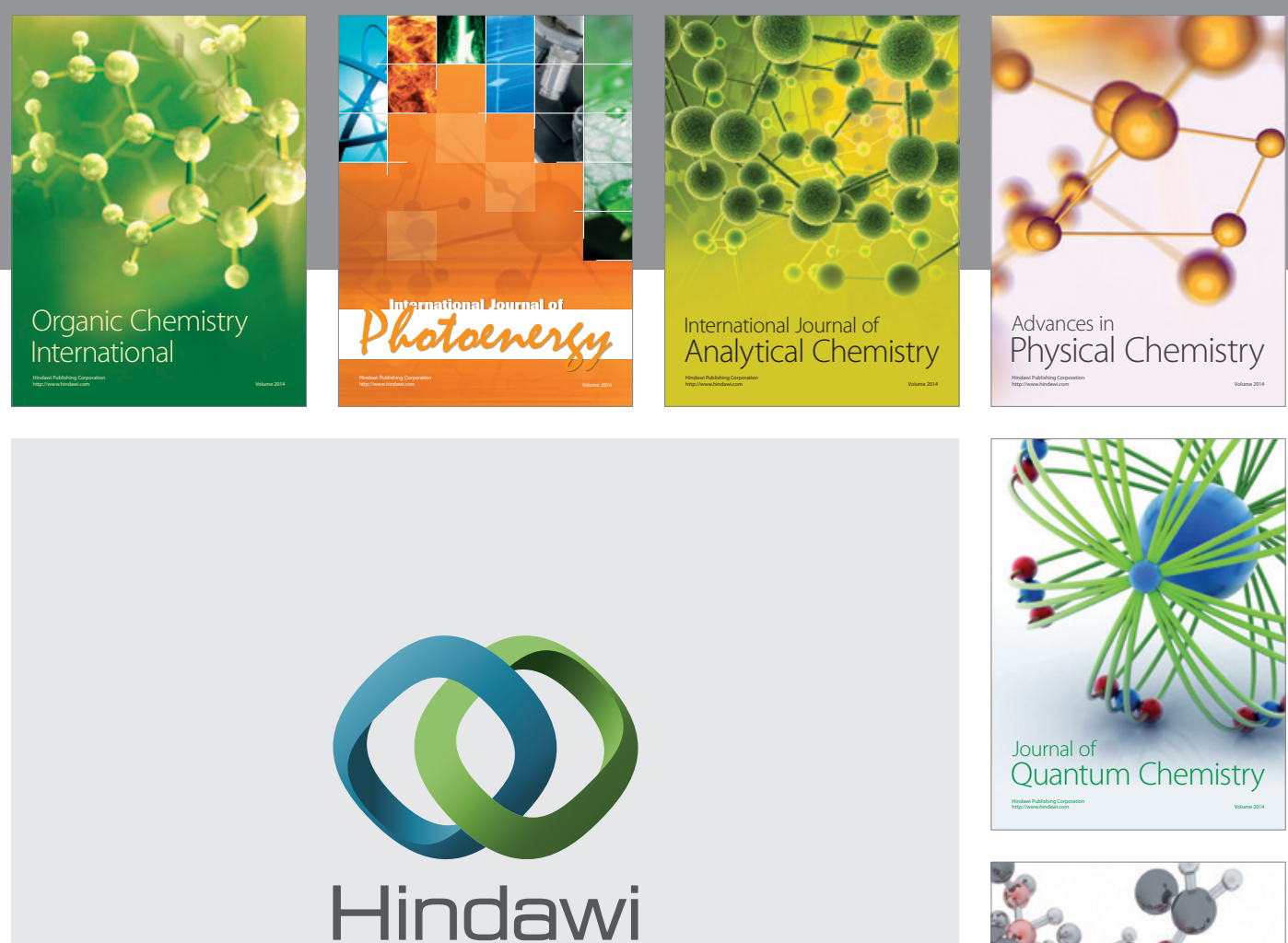

Submit your manuscripts at

http://www.hindawi.com

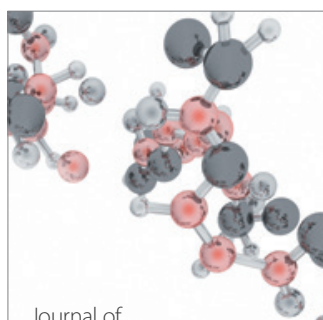

Analytical Methods

in Chemistry

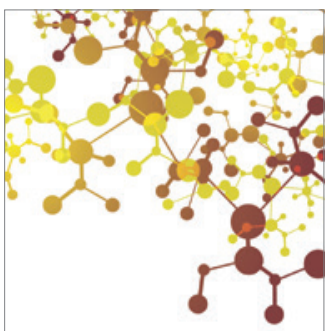

Journal of

Applied Chemistry

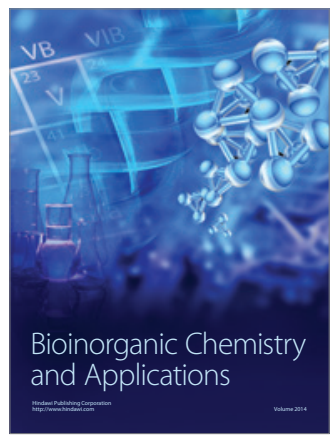

Inorganic Chemistry
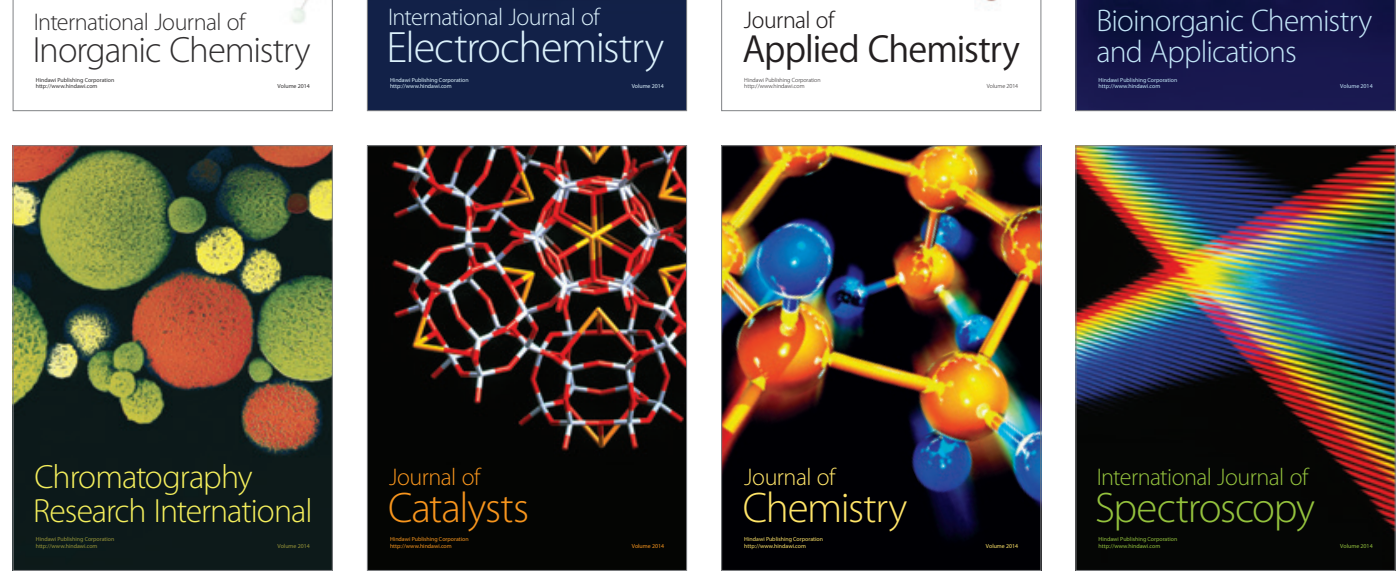